\title{
US budget deal gives small increases to research
}

\section{US President Obama expected to sign legislation that also includes $\$ 5.4$ billion for Ebola fight.}

\section{Sara Reardon, Mark Zastrow \& Lauren Morello}

14 December 2014

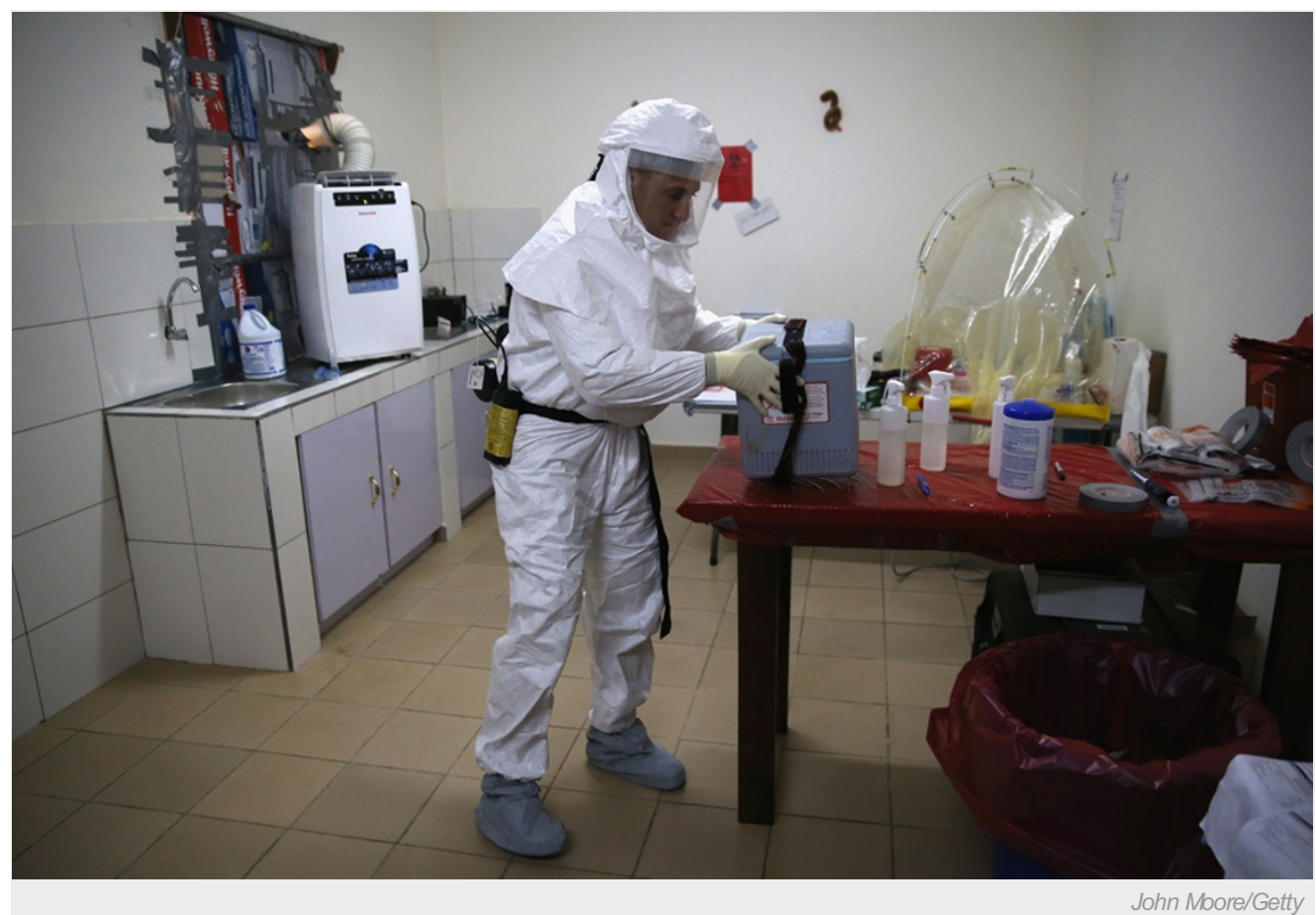

The US government is poised to spend $\$ 5.2$ billion on Ebola aid and research in fiscal year 2015 .

NASA and the US National Science Foundation would see their budgets rise in fiscal year 2015 under a US $\$ 1.1$ trillion spending bill approved by the US Congress.

The measure, passed by the House on 11 December and by the Senate on 13 December, also includes an additional $\$ 5.4$ billion in aid and research funds for the Ebola epidemic in West Africa. US President Barack Obama is expected to sign the bill into law, finalizing the budget for US agencies through 30 September 2015 (see 'Budget highlights').

Overall, the bill would increase spending on research and development by $1.7 \%$ above the 2014 level — in lockstep with the rate of inflation. But the share of money going to basic research would decline by $0.3 \%$ in real dollars, according to Matt Hourihan, director of the research and development budget and policy programme at the American Association for the Advancement of Science in Washington DC.

"The problem is it continues the slow bleed," says Michael Lubell, the director of public affairs at the American Physical Society in Washington DC. With fiscally conservative Republicans set to control both houses of Congress next year, the budget picture is not likely to improve, he adds - although Obama's ability to veto legislation should ward off large funding cuts.

The Ebola bolus includes $\$ 25$ million for the Food and Drug Administration for purposes such as expediting drug and vaccine approval. The Department of State, which includes the Agency for International Development, would receive an additional $\$ 2.5$ billion for Ebola programmes. The Centers for Disease Control and Prevention would get $\$ 1.78$ billion for its Ebola work in the United States and Africa, and the National Institute of Allergy and Infectious Disease (NIAID) would receive \$238 million for research that includes testing experimental Ebola vaccines.

\section{Budget highlights}




How science agencies fared in the budget (US\$ millions).
\begin{tabular}{|l|l|l|l|}
\hline Agency & $\mathbf{2 0 1 4}$ actual & $\mathbf{2 0 1 5}$ request & $\mathbf{2 0 1 5}$ actual \\
\hline National Institutes of Health & 30,003 & 30,203 & 30,084 \\
\hline Centers for Disease Control and Prevention & 5,882 & 5,474 & 6,023 \\
Food and Drug Administration & $2,640 \dagger$ & 2,584 & 2,597 \\
National Science Foundation & 7,142 & 7,255 & 7,344 \\
NASA (science) & 5,151 & 4,972 & 5,245 \\
Department of Energy Office of Science & 5,066 & 5,111 & 8,136 \\
Environmental Protection Agency & 8,200 & 7,890 & 5,381 \\
National Oceanic and Atmospheric Administration & 5,322 & 5,497 & 1,045 \\
US Geological Survey & 1,032 & 1,073 & \\
\hline
\end{tabular}

†Includes one-time transfer of $\$ 79$ million in user fees.

Source: Source: US Congress \& White House Office of Management and Budget

\section{Tough times at the NIH}

But the NIAID's parent agency, the National Institutes of Health $(\mathrm{NIH})$, would not fare as well overall. The spending legislation would increase the $\mathrm{NIH}$ budget by only $\$ 150$ million over the 2014 level — roughly $0.5 \%$. That is disappointing, given that inflation is rising at $2 \%$ per year, says Jennifer Zeitzer, deputy director of public affairs at the Federation of American Societies for Experimental Biology in Bethesda, Maryland.

"There's an increase, which is something to be grateful for, but the fact is that we are still going backwards," Zeitzer says.

The NIH budget includes $\$ 65$ million for the agency's portion of the Brain Research through Advancing Innovative Neurotechnologies (BRAIN) Initiative - a \$25-million increase over 2014, but much less than NIH's wished-for $\$ 400$ million to $\$ 500$ million per year for the programme.

\section{Science up at NASA}

The outlook is better at NASA, which benefited from a roster of bipartisan supporters in Congress. The agency would receive $\$ 18$ billion, an increase of $\$ 364$ million above the 2014 level.

The agency's science directorate would receive just over $\$ 5.2$ billion, a bump of $\$ 94$ million from 2014 . Within the directorate, funding for planetary science, astrophysics and heliophysics would increase, while Earth science would take a slight hit.

One big winner at NASA is the Stratospheric Observatory for Infrared Astronomy (SOFIA), a telescope mounted on a Boeing 747 jet. Obama proposed grounding SOFIA in his 2015 budget request released in March, but the programme - developed with the German Aerospace Center (DLR) — found support in Congress.

The bill would also set aside $\$ 100$ million for a mission to Jupiter's moon Europa, whose underground ocean is considered one of the most hospitable places for life in the Solar System. NASA has not yet decided on a mission concept, but the general idea of heading to Europa has the backing of Representative John Culberson, the Texas Republican who in January will take the helm of the House subcommittee that oversees NASA's funding.

\section{NSF rises, energy department flat}

The National Science Foundation (NSF) would receive a 2.4\% bump over 2014 — "a pleasant surprise", says Hourihan. Research spending will increase by a total of $\$ 125$ million across the NSF's six directorates. That includes the agency's programmes on social, behavioural and economic sciences, which House Republicans have sought to cut in recent years.

The Department of Energy's science budget would remain flat at $\$ 5.1$ billion, although the spending deal approved by Congress would reverse cuts to nuclear-fusion research that were sought by the White House. However, the bill also contains language threatening to withhold the US contribution to ITER, the multibillion-euro international fusion consortium, if the beleaguered project, which is 11 years behind schedule, does not implement management changes. 
Nature | doi:10.1038/nature.2014.16553 